\title{
RP-HPLC Method for Simultaneous Estimation of Atenolol, Hydrochlorothiazide and Losarton in Tablet Dosage form
}

\author{
R. SHARMA, S. KHANNA and G. P. MISHRA
}

School of Pharmacy, Devi Ahilya Vishwavidyalaya, Takshshila Campus, Khandwa Road, Indore-452017, M.P., India

rbsm73@yahoo.co.in

Received 9 July 2012 / Accepted 29 July 2012

\begin{abstract}
The present work describes a simple, sensitive, accurate and rapid reverse phase high performance liquid chromatographic method for simultaneous estimation and validation of atenolol, hydrochlorothiazide and losartan in tablet dosage form. Chromatography was performed on a $25 \mathrm{~cm} \times$ $4.6 \mathrm{~mm}$ i.d, $5 \mu \mathrm{m}$ particle, C18 column with use of mixture of (A) acetonitrile, methanol (65:35) and (B) $10 \mathrm{mM}$ sodium dihydrogen phosphate monohydrate buffer with $0.4 \% \mathrm{v} / \mathrm{v}$ triethylamine and mixture of $\mathrm{A}: \mathrm{B}(60: 40 \mathrm{v} / \mathrm{v})$ adjusted to $\mathrm{pH} 3.0$ with $o$-phosphoric acid $(5 \% \mathrm{v} / \mathrm{v})$ was used as a mobile phase at a flow rate of $1.5 \mathrm{~mL} / \mathrm{min}$. The chromatograms were recorded at $230 \mathrm{~nm}$. The linearity range was found 1-25 $\mu \mathrm{g} / \mathrm{mL}, 1-25 \mu \mathrm{g} / \mathrm{mL}$ and $1-25 \mu \mathrm{g} / \mathrm{mL}$ for atenolol, hydrochlorothiazide and losartan respectively.
\end{abstract}

Keywords: RP-HPLC, Simultaneous Estimation, Validation, Atenolol, Hydrochlorothiazide, Losartan

\section{Introduction}

Atenolol (ATN) is a selective $\beta_{1}$ receptor antagonist, belonging to the group of beta blockers and a class of drugs used primarily in cardiovascular diseases. It is $(R S)$-2-\{4-[2-hydroxy-3(propan-2-ylamino) propoxy] phenyl $\}$ acetamide. Hydrochlorothiazide (HCTZ) is a first-line diuretic drug of the thiazide class that helps the body get rid of excess water while still keeping calcium. Hydrochlorothiazide is 6-chloro-1, 1-dioxo-3, 4-dihydro- $2 \mathrm{H}-1,2,4$ benzothia-diazine-7-sulfonamide. The major site of action in the nephron appears on an electroneutral $\mathrm{Na}^{+}-\mathrm{Cl}^{-}$co-transporter by competing for the chloride site on the transporter. By impairing $\mathrm{Na}$ transport in the distal convoluted tubule, hydrochlorothiazide induces a natriuresis and concomitant water loss. Losartan (LOS) is an angiotensin II receptor antagonist drug used mainly to treat high blood pressure hypertension. It may also delay progression of diabetic nephropathy and is also indicated for the reduction of renal disease progression in patients with type 2 diabetes ${ }^{1-4}$. The structure of the components of formulation were depicted in the Figure 1. The spectrophotometric determination of atenolol in tablets ${ }^{5}$ and simultaneous determination of captopril and hydrochlorothiazide in human plasma by reverse-phase HPLC ${ }^{6}$ was reported in the literature. Simultaneous determination 
of amiloride $\mathrm{HCl}$, hydrochlorothiazide and atenolol in combined formulations by derivative spectroscopy ${ }^{7}$ was also studied by Prasad et al. Comparison of UV and second derivative spectrophotometric ${ }^{8}$ and HPLC methods for the determination of losartan in tablets and development and validation of an UV derivative spectrophotometric determination of losartan potassium in tablets ${ }^{9}$ was reported by Lastra et al. The present work describes a simple, sensitive, accurate and rapid reverse phase high performance liquid chromatographic method for simultaneous estimation and validation of atenolol, hydrochlorothiazide and losartan in tablet dosage form.<smiles>CC(C)N(CCO)CCOc1ccc(CC(N)=O)cc1</smiles>

(a)<smiles>NS(=O)(=O)c1cc2c(cc1Cl)NC=NS2(=O)=O</smiles>

(b)

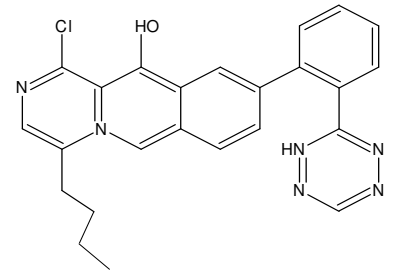

(c)

Figure 1. Chemical structures of (a) Atenolol, (b) Hydrochlorothiazide and (c) Losartan.

\section{Experimental}

Pure samples of atenolol, hydrochlorothiazide and losartan were obtained as gift sample from Plethico Pharmaceuticals Pvt. Ltd., Indore, India and tested for purity. The solid dosage form (Tozar-ath tablets) was procured from local market (Label claim: $50 \mathrm{mg}$ atenolol, $12.5 \mathrm{mg}$ hydrochlorothiazide and $50 \mathrm{mg}$ losartan). All the chemical and reagents used were of HPLC grade and purchased from Spectrochem, Mumbai, India.

\section{Equipment used}

Shimadzu HPLC (LC-10 AT VP) system; LC system used consist of pump (Model SHIMADZU; LC- 10 AT VP) with universal loop injector (Rheodyne 7725 i) of injection capacity $20 \mu \mathrm{L}$. Detector consists of photodiode array detector SPD-10 AVP, SHIMADZU; the reverse phase column used was Luna $\mathrm{C}_{18}(5 \mu \mathrm{M}, 25 \mathrm{~cm} \times 4.6 \mathrm{~mm}$ i.d) phenomenex, USA, at ambient temperature.

\section{Preparation of standard and sample solutions}

The equivalent of $10 \mathrm{mg}$ each of ATN, HCTZ and LOS were accurately weighed and transferred to $100 \mathrm{~mL}$ volumetric flasks separately and dissolved in $25 \mathrm{~mL}$ of methanol to prepare standard stock solutions. After the immediate dissolution, the volume was made up to the mark with solvent. These standard stock solutions were observed to contain 100 $\mu \mathrm{g} / \mathrm{mL}$ of ATN, HCTZ and LOS. Twenty tablets of Tozar-ATH were taken and their average weight was determined, they were crushed to fine powder. Then powder equivalent to $50 \mathrm{mg}$ of ATN was taken in $100 \mathrm{~mL}$ volumetric flask and dissolved in $75 \mathrm{~mL}$ of solvent (methanol) with vigorous shaking for 5-10 minutes. The supernatant liquid was transferred to $100 \mathrm{~mL}$ of volumetric flask through a Whatman \#41 filter paper. The residue was washed twice with methanol and the combined filtrate was made up to $100 \mathrm{~mL}$ mark. After that 10 $\mathrm{mL}$ of the above solution was diluted up to $100 \mathrm{~mL}$ with solvent (mobile phase). Six replicates of sample solutions were prepared in required concentrations of all the three drugs. Then $20 \mu \mathrm{L}$ of each replicates were injected into the system. From the chromatograms it was observed that ATN, HCTZ and LOS were eluted at 1.597, 2.191 and 5.450 minutes respectively. The concentrations of the all three drugs were extrapolated from their respective calibration curves by using the area. 
The mobile phase was a mixture of (A) containing acetonitrile : methanol (65:35) and (B) containing $10 \mathrm{mM}$ sodium dihydrogen phosphate monohydrate buffer and finally $\mathrm{pH}$ of the mobile phase(A):(B) $(60: 40 \mathrm{v} / \mathrm{v})$ was adjusted to 3.0 with o-phosphoric acid $(5 \% \mathrm{v} / \mathrm{v})$ at a flow rate of $1.5 \mathrm{ml} / \mathrm{min}$, was used to sharpen the peak. The run time was less then $12 \mathrm{~min}$. Before analysis, both mobile phase and sample solutions were degassed by sonication and filtered through $0.2 \mu \mathrm{m}$ filter paper. The analytes were monitored at $230 \mathrm{~nm}$.

\section{Construction of calibration curves}

From the standard stock solutions of all the three drugs, different dilutions were prepared and chromatographed and the peak areas were measured.

Calibration plot of concentration against peak area were then constructed for Atenolol, Hydrochlorothiazide and Losartan. From the calibration curve it was clear that ATN, HCTZ and LOS have linearity range between 1-25 $\mu \mathrm{g} / \mathrm{mL}, 1-25 \mu \mathrm{g} / \mathrm{mL}$ and $1-25 \mu \mathrm{g} / \mathrm{mL}$ respectively. Unknown assay samples were quantified by reference to these calibration plots. The overlain spectra of the formulation are reported in Figure 2.

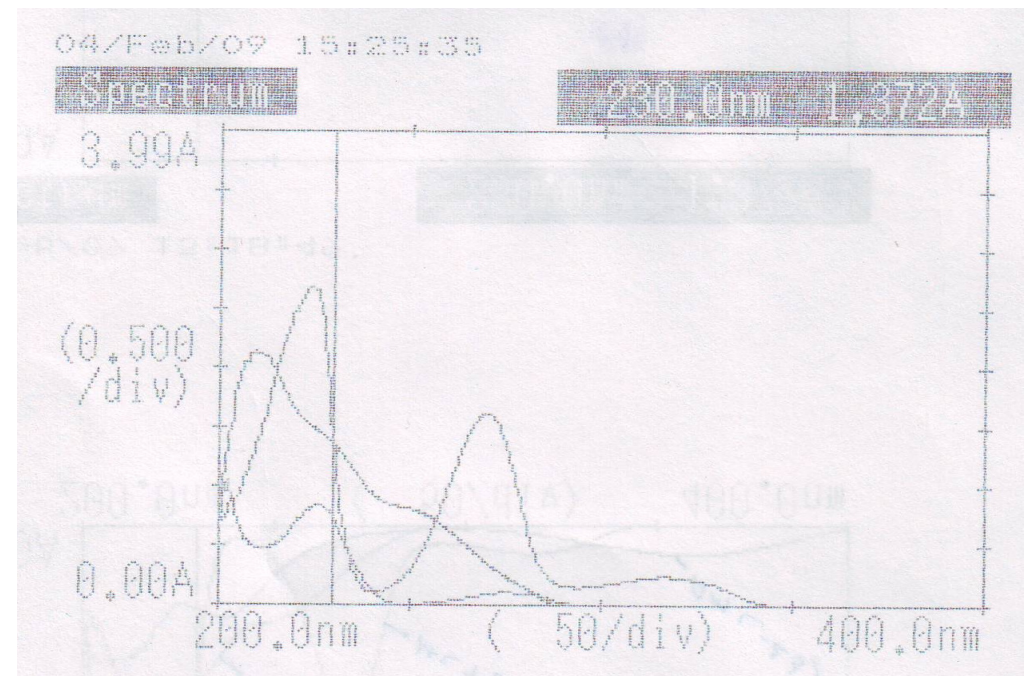

Figure 2. Overlain spectra of atenolol, hydrochlorothiazide and losartan

\section{Analysis of pharmaceutical formulation}

Before assay of the formulations of six replicates of the required dilutions were prepared from the stock solution and sonicated for $10 \mathrm{~min}$. The solutions $(20 \mu \mathrm{L})$ were then injected for quantitative analysis. The amounts of ATN, HCTZ and LOS per tablets were calculated by extrapolating the peak area from the calibration curve. The results are reported in Table 1.

Table 1. Results from assay of the marketed formulation

\begin{tabular}{ccccccc}
\hline Drug & $\begin{array}{c}\text { Label claim } \\
(\mathrm{mg} \backslash \text { Tablet }) \mathrm{n}=6\end{array}$ & $\begin{array}{c}\text { Amount } \\
\text { Found in mg }\end{array}$ & $\begin{array}{c}\text { Drug } \\
\text { Concentration, } \%\end{array}$ & SD & COV, & SE \\
\hline ATN & 50 & 50.650 & 99.97 & 1.08 & 1.07 & 0.44 \\
HCTZ & 12.5 & 12.622 & 100.98 & 0.47 & 0.47 & 0.29 \\
LOS & 50 & 49.987 & 101.30 & 0.88 & 0.73 & 0.42 \\
\hline
\end{tabular}

S.D- standard deviation; COV-coefficient of variance; S.E-standard error 
Under the optimum chromatographic conditions, the retention times obtained for ATN, HCTZ and LOS were 1.597, 2.191 and 5.450 minutes respectively and their chromatograms were recorded and given in the Figure 3. Capacity factors, tailing factors and number of theoretical plates are given in Table 2.

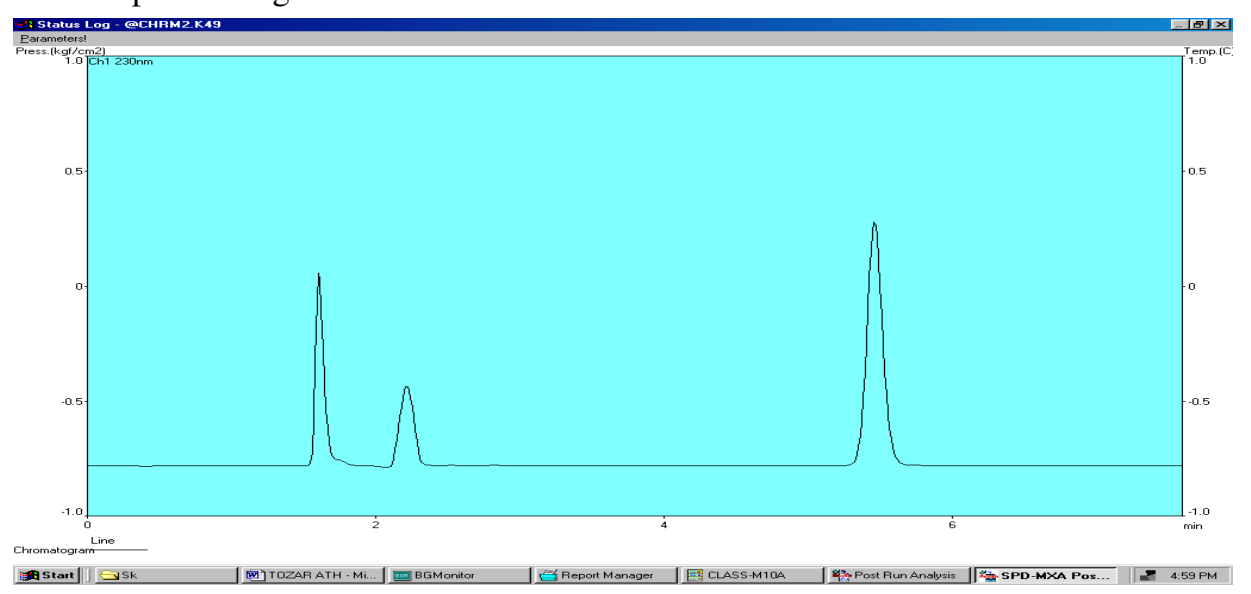

Figure 3: A typical chromatogram of atenolol, hydrochlorothiazide and losartan

Table 2. System suitability parameters

\begin{tabular}{cccc}
\hline Property & ATN & HCTZ & LOS \\
\hline$R^{t}$ & 3.152 & 4.211 & 9.010 \\
$T_{f}$ & 1.06 & 1.33 & 1.11 \\
$K^{\prime}$ & 0.21 & 0.35 & 2.04 \\
$N$ & 7235 & 9654 & 5355 \\
$R_{s}$ & - & 6.55 & 11.65 \\
\hline
\end{tabular}

$R t$, retention time; Tf, tailing factor; $k^{\prime}$, capacity factor; $N$, number of theoretical plates $R s$, resolution

\section{Recovery studies}

To perform the accuracy of the developed method and to study the interference of formulation additives, analytical recovery experiments were carried out by standard addition method. The results of the analysis are reported in Table 3 .

Table 3. Results of recovery studies

\begin{tabular}{cccccc}
\hline Drug & $\begin{array}{c}\text { Amount taken, } \\
\mu \mathrm{g} \mathrm{m} \mathrm{L} \mathrm{L}^{-1}\end{array}$ & \multicolumn{2}{c}{$\begin{array}{c}\text { Amount added } \\
\% \mu \mathrm{g} \mathrm{m} \mathrm{L}^{-1}\end{array}$} & $\begin{array}{c}\text { Recovery, } \\
\%, \pm \text { S.D }\end{array}$ & $\begin{array}{c}\text { COV, } \\
\%\end{array}$ \\
\hline \multirow{3}{*}{ ATN } & \multirow{2}{*}{50} & 80 & 40 & 99.92 & 0.905 \\
& & 100 & 50 & 100.17 & 0.483 \\
& & 120 & 60 & 100.44 & 0.852 \\
HCTZ & \multirow{2}{*}{12.5} & 100 & 10 & 100.00 & 0.654 \\
& & 120 & 15 & 100.65 & 0.584 \\
& & 80 & 40 & 100.01 & 0.187 \\
LOS & 50 & 100 & 50 & 99.95 & 0.419 \\
& & 120 & 60 & 99.90 & 0.443 \\
\hline
\end{tabular}

S.D., standard deviation; COV, coefficient of variance 


\section{Validation}

The method was validated for linearity, accuracy, precision, repeatability, selectivity and specificity. Accuracy was studied by measurement of recovery at three different levels 80 , 100 and $120 \%$ of the amount expected in the formulation, in accordance with ICH guidelines ${ }^{10-11}$. Precision was measured both intra-day and inter-day. In the intra-day study the concentrations of all three drugs were calculated three times on the same day at intervals of an hour. In the inter-day study the concentrations of all the three drugs were measured on three different days. The selectivity and specificity of the method were validated by injecting solutions containing all the three drugs; three sharp peaks were obtained for all the three drugs. The limits of detection and quantitation of the method were studied to detect the lowest amount of analyte and quantitative determination of analyte in a sample respectively. The results are reported in Table 4.

Table 4. Results from determination of intra-day and inter-day precision and LOD and LOQ

\begin{tabular}{|c|c|c|c|c|c|c|}
\hline \multirow{2}{*}{ Drug } & \multirow{2}{*}{$\begin{array}{c}\text { Intra-day precision, } \\
\text { COV }, \%\end{array}$} & \multicolumn{3}{|c|}{ Inter-day precision, $\mathrm{COV}, \%$} & \multirow{2}{*}{$\begin{array}{c}\text { LOD } \\
\text { ng } \mathrm{mL}^{-1}\end{array}$} & \multirow{2}{*}{$\begin{array}{c}\text { LOQ } \\
\mathrm{ng} \mathrm{mL} \mathrm{mL}^{-1}\end{array}$} \\
\hline & & Day 1 & Day 2 & Day 3 & & \\
\hline ATN & 1.652 & 1.420 & 1.681 & 1.401 & 0.014 & 0.933 \\
\hline HCTZ & 0.769 & 0.525 & 0.998 & 0.732 & 0.118 & 0.343 \\
\hline LOS & 1.013 & 1.035 & 1.238 & 1.101 & 0.129 & 0.129 \\
\hline
\end{tabular}

A Mean from six determinations $C O V$, coefficient of variance; $L O D$, limit of detection; $L O Q$, limit of quantitation

\section{Results and Discussion}

Different column chemistry, solvent type, solvent strength (volume fraction of organic solvents in the mobile phase and $\mathrm{pH}$ of the buffer solution), detection wavelength and flow rate were varied and used to optimized the chromatographic conditions that giving the best separation in the chromatogram. The mobile phase conditions were optimized so that the components were not interfered with the solvent and excipients. Other criteria like time required for analysis, appropriate $k$ range for eluted peaks, assay sensitivity, solvent noise and use of the same solvent system for extraction of drug from formulation matrices during drug analysis were also considered.

A series of aqueous mobile phases containing sodium dihydrogen phosphate buffer solutions of different $\mathrm{pH}$ in combination with different volume fractions of acetonitrile as modifiers were also tested. The best result was obtained at $\mathrm{pH} 3$ for sodium dihydrogen phosphate buffer ( $\mathrm{pH}$ adjusted with $o$-phosphoric acid). From the study it was found that best result was obtained in a quality separation in terms of peak symmetry, resolution, reasonable run time and other parameters by use of mixture of (A) acetonitrile, methanol (65:35) and (B) $10 \mathrm{mM}$ sodium dihydrogen phosphate monohydrate buffer with $0.4 \% \mathrm{v} / \mathrm{v}$ triethylamine and mixture of $\mathrm{A}: \mathrm{B}(60: 40 \mathrm{v} / \mathrm{v})$ adjusted to $\mathrm{pH} 3.0$ with $o$-phosphoric acid $(5 \% \mathrm{v} / \mathrm{v})$ was used as a mobile phase for the formulations. The flow rate was determined by testing the effect of different flow rate on the peak area and resolution, flow rate of $1.5 \mathrm{~mL} / \mathrm{min}$ found optimum.

All experiments were performed at ambient temperature. The values obtained for $k$ and $R S(1<k<10, R S>2)$ show these chromatographic conditions are appropriate for separation and quantification of both the compounds. The number of plates $(N)$ is a measure of column efficiency; which shows the high separation efficiency of the column used. 


\section{Conclusion}

A new, reversed-phase HPLC method has been developed for simultaneous analysis of ATN, HCTZ and LOS in a solid formulation. It was shown above that the method was accurate, reproducible, repeatable, linear, precise and selective, proving the reliability of the method. The run time was relatively short, i.e. $10 \mathrm{~min}$, which enables rapid quantitation of many samples in routine and quality control analysis of formulations. The optimized solvent system was used throughout the experimental work and no interference from any excipient was observed. These results have shown that method could find practical application as a quality-control tool for simultaneous analysis of all three drugs from their combined dosage forms in quality-control laboratories.

\section{Acknowledgment}

The authors are grateful to Plethico Pharmaceuticals Pvt. Ltd Indore, India for providing gift samples and also thankful Mr. Suresh Prajapati for providing assistance during work.

\section{References}

1. Indian Pharmacopoeia, Vol. III, New Delhi. The controller of publication Govt. of India, 2007, 164.

2. Goodman and Gilman, the Pharmacological basis of therapeutics, $10^{\text {th }}$ Edition, New York, McGraw Hill Book, 2001, 1701.

3. Martindale, The Complete Drug Reference, Pharmaceutical Press, London, $33^{\text {rd }}$ Edition, 2003, 966.

4. The Merck index, An encyclopedia of chemicals, drugs and biological, $13^{\text {th }}$ Merck Research laboratories, Division of Whitehouse Station, NJ Merck and Co Inc., 2001, 140.

5. Bashir N, Shah S W H, Bangesh M and Riazullah R, J Sci Ind Res., 2011, 70(1), 51-54.

6. Huang T, He Z, Yang B, Shao L, Zheng X and Duan G, J Pharm Biomed Anal., 2006, 41(2), 644-648.

7. Prasad C V, Parihar C, Sunil K and Parimoo P, J Pharm Biomed Anal., 1998, 17, 877.

8. Ulu S T and Saglik S, Turk J Pharm Sci., 2004, 1, 165-175.

9. Lastra O C, Lemus I G, Sanchez H J and Perez R F, J Pharm Biomed Anal., 2003, 33(2), 175-180.

10. Sharma R, Mishra G P and Chaturvedi S C, J Chem., 2010, 3(7), 947-952.

11. ICH guidelines on Validation of Analytical Procedures, Text and Methodology Q2 (R1), FDA, Published in the Federal Register, 1995, 60. 